\title{
Notch Signaling in Neuroendocrine Tumors
}

\author{
Judy S. Crabtree ${ }^{1,2 \star}$, Ciera S. Singleton ${ }^{1}$ and Lucio Miele ${ }^{1,2}$ \\ ${ }^{1}$ Department of Genetics, Louisiana State University Health Sciences Center, New Orleans, LA, USA, ${ }^{2}$ Stanley S. Scott \\ Cancer Center, Louisiana State University Health Sciences Center, New Orleans, LA, USA
}

Carcinoids and neuroendocrine tumors (NETs) are a heterogeneous group of tumors that arise from the neuroendocrine cells of the Gl tract, endocrine pancreas, and the respiratory system. NETs remain significantly understudied with respect to molecular mechanisms of pathogenesis, particularly the role of cell fate signaling systems such as Notch. The abundance of literature on the Notch pathway is a testament to its complexity in different cellular environments. Notch receptors can function as oncogenes in some contexts and tumor suppressors in others. The genetic heterogeneity of NETs suggests that to fully understand the roles and the potential therapeutic implications of Notch signaling in NETs, a comprehensive analysis of Notch expression patterns and potential roles across all NET subtypes is required.

Keywords: Notch, neuroendocrine tumors, carcinoid, pNET, small-cell lung cancer, SCLC

\section{INTRODUCTION}

Notch has been studied for many years in the context of cancer, and over the years, the signaling pathways involved have become clearer. However, as these pathways are elucidated, the complexity of Notch signaling is revealed as well. It is now known that in addition to canonical Notch signaling where the activated Notch receptors can play tumor suppressive roles in some cancer types and oncogenic roles in others, non-canonical signaling is also active in some cell types and impacts signaling through phosphatidylinositol 3' kinase (PI3K)/Akt, mTOR, NF-kB, and $\beta$-catenin (1-6). In neuroendocrine tumors (NETs), these same signaling pathways, as well as hairy enhancer of split 1 (Hes-1)/achaete-scute complex-like 1 (ASCL-1), have been shown to impact tumorigenesis via Notch signaling (7-14). Translationally, many of these pathways have modulatory or inhibitory drugs in development that may be applied to the treatment of NETs, but the role of Notch signaling in this diverse set of tumors must be more clearly defined. Here, we outline current knowledge of the Notch canonical and non-canonical signaling in NETs as well as highlight understudied areas.

\section{CANONICAL NOTCH SIGNALING}

The Notch signaling pathway has long been recognized as a central player in cellular processes, such as proliferation, stem cell maintenance, and differentiation during both embryonic and adult development. Notch signaling is evolutionarily conserved across species and relies on the presence of the Notch receptor binding in trans to ligand present on a neighboring cell. In canonical signaling, ligand binding promotes the intracellular cleavage of the receptor by metalloproteases to release the active form of Notch, the Notch intracellular domain (NICD), which translocates into the 


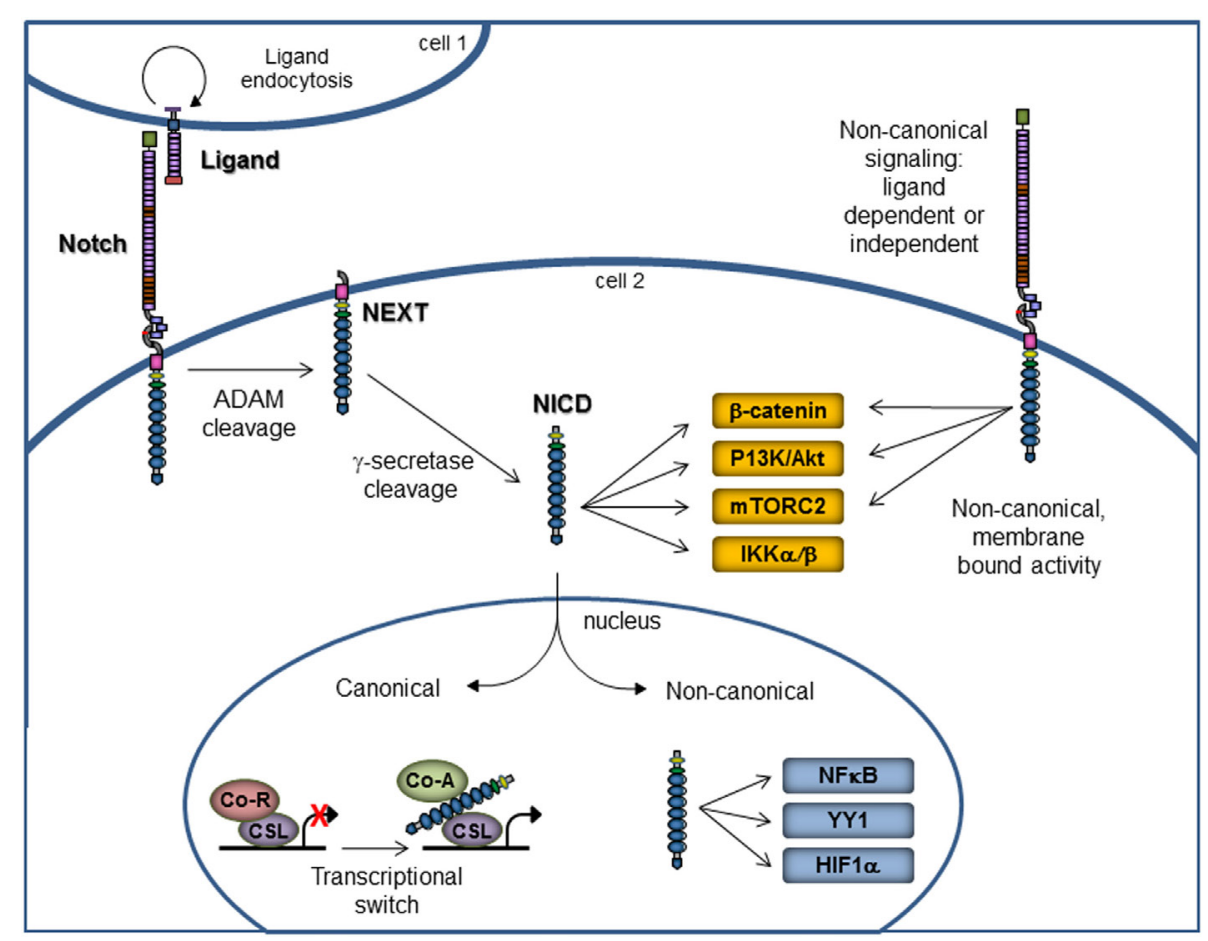

FIGURE 1 | Notch canonical and non-canonical signaling. Notch signaling via the canonical pathway is on the left portion of the figure. Membrane-bound Notch receptor is activated by binding with ligand on a neighboring cell, which results in cleavage by ADAM metalloproteases, followed by cleavage with $\gamma$-secretase. These cleavage events release the NICD, which then enters the nucleus to affect the gene transcription. The non-canonical signaling pathway is on the right portion of the figure and illustrates that non-canonical signaling may occur either in the presence or absence of ligand. Further, the signaling may occur via the membrane-bound, uncleaved Notch receptor or via the NICD. Non-canonical Notch signaling is independent of CSL and allows for interaction with PI3K/AKT/ mTORC2, Wnt/ $\beta$-catenin, IKK $\alpha / \beta$, NFкB, YY1, and HIF1 $\alpha$ pathways at the cytoplasmic and/or nuclear level. Abbreviations: ADAM, a disintegrin and metalloprotease; NEXT, Notch extracellular truncation; NICD, Notch intracellular domain; Co-R, corepressor; Co-A, coactivator.

nucleus and binds to transcription factor CBF-1/Suppressor of Hairless/LAG-1 (CSL), also known as RBP-Jא, to activate expression of Notch-responsive genes (Figure 1) (15-18).

The number of Notch receptor genes varies by species, with Drosophila containing one Notch receptor, Caenorhabditis elegans having two redundant receptors, and mammals containing four Notch receptors, Notch1-4. The Notch receptors contain an extracellular domain that includes multiple epidermal growth factor (EGF)-like repeats that are essential for ligand binding and vary in length across the four mammalian receptors. The intracellular portion of Notch is critical for transmission of cellular signals and contains an RBP-Jא association module (RAM) domain, a nuclear localization signal (NLS), a seven ankyrin repeat $(\mathrm{ANK})$ domain, and a transactivation domain that contains conserved proline/glutamic acid/serine/threonine-rich (PEST) motifs (Figure 2). The ligands for Notch receptors are varied and have been extensively reviewed in Ref. (17). In mammals, Notch ligands include Delta-like 1 (DLL1) and Delta-like 4 (DLL4), homologous to Drosophila Delta, along with Jagged 1 (JAG1) and Jagged 2 (JAG2), homologous to Drosophila Serrate. Delta-like 3 (DLL3) may be an inhibitory ligand that sequesters Notch receptors in the cytoplasm (19). These ligands are responsible for the majority of known canonical Notch signaling effects and like Notch have multiple EGF-like repeats in their extracellular domains. These type 1 transmembrane proteins all contain an $\mathrm{N}$-terminal sequence that along with the DSL (Delta/Serrate/ Lag2) motif and the first two EGF-like repeats are required for ligand-receptor binding. In contrast to the DLL ligands, the Jagged ligands have almost twice the number of EGF repeats and also contain an additional cysteine-rich region. The intracellular portion of all Notch ligands lacks major homology with the exception that some, but not all, ligands contain multiple lysine residues and a C-terminal PDZ (PSD-95/Dlg/ZO-1) domain. Stimulation of the Notch signaling pathway ultimately results in the transcriptional activation of a discrete set of genes by the formation of a Notch transcriptional complex at the promoters of target genes or within enhancer or superenhancer regions (20). This complex includes the NICD, which translocates into the nucleus and displaces a corepressor complex to bind to CSL, first through interaction with the RAM domain followed by the ANK domain. This binding mediates a transcriptional switch to activate transcription from promoters containing CSL binding sites (GTGGGAA) and is dependent on the formation of a ternary complex, including one of mastermind-like 1-3 (MAML1-3) coactivators (21), and ski-interacting protein (SKIP) (22-24). This tertiary complex in turn recruits additional coactivator proteins such as the histone acetyltransferases CREB-binding protein (CBP)/p300 (25) or p300/CBP-associated factor (PCAF)/ 


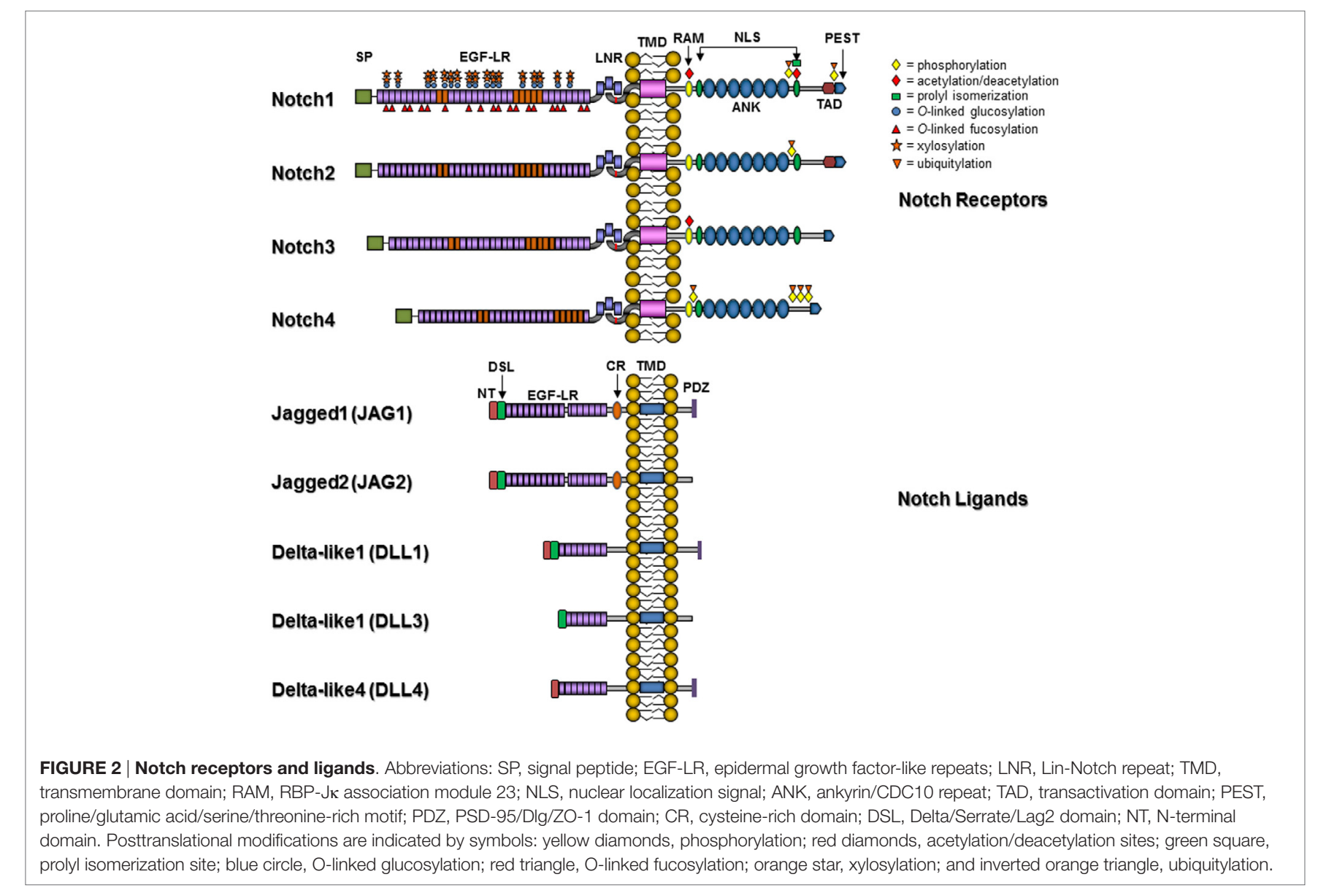

GCN5 (26). In the absence of NICD, CSL actively represses transcription from Notch target genes, and a large number of repressor complex components have been identified, including histone deacetylases (27), silencing mediator for retinoid and thyroid hormone receptor/nuclear receptor corepressor (SMRT/ NCoR) (28), SMRT/HDAC-1-associated repressor protein/ Msx2-interacting nuclear target (SHARP/MINT)/SPEN $(29,30)$, CSL-interacting corepressor (CIR) (31), hairy and enhancer of split 1 (Hes1) (32), hairy-related transcription factor 1 (HRT1) (32), c-Jun N-terminal kinase (JNK)-interacting protein-1 (JIP1) (33), and lysine-specific demethylase 5A/retinoblastoma-binding protein 2 (KDM5A/RBP2) (34), among others.

Endogenous NICD is relatively short lived. It is transiently present at Notch target promoters in response to ligand and degrades rapidly in part due to phosphorylation of the C-terminal PEST domain by cyclin C/cyclin-dependent kinase (CDK) 8 (35). Phosphorylation of the PEST domain is followed by ubiquitinylation and subsequent proteasome degradation $(36,37)$. Furthermore, phosphorylation near the ankyrin repeats of NICD has also been reported to negatively regulate Notch transcriptional activation by interfering with the formation of the Notch activation complex (38). On the contrary, phosphorylation of NICD by glycogen synthase kinase $3 \beta$ (GSK3 $\beta$ ) occurs in a region C-terminal to the ANK repeats and increases the stability of NICD (39). Fringe enzymes ( $N$-acetylglucosaminyltransferases) influence binding affinity between Notch receptors and specific EGF-like repeats by glycosylation (40-42). Glycosylation by fringe results in elongation of O-linked fucose residues on particular EGF-like repeats in Notch and prevents Notch activation by Jagged ligands, but not by Delta-like ligands $(43,44)$. Another form of O-linked carbohydrate modification on Notch receptors is O-glucose, which is attached to serine residues by the $O$-glucosyltransferase Rumi/POGLUT1 (45). O-glycosylated Notch EGF-like repeats can be further modified by the addition of xylose by glucoside xylosyltransferase (GXYLT)1 and GXYLT2 and xyloside xylosyltransferase, resulting in negative regulation of Notch signaling (46-48). Acetylation by CBP/p300 and PCAF/GCN5 enhances NICD stability $(49,50)$, as does prolyl isomerization by Pin1 (51), whereas deacetylation of NICD and histones by Sirtuin 1 (SIRT1) inhibits Notch signaling $(52,53)$. These posttranslational modifications may also be Notch paralog specific. For example, the Notch4 intracellular domain (Notch4-ICD) is the only Notch paralog with sites for AKT phosphorylation. Notch4-ICD that is phosphorylated by AKT then binds to $14-3-3 \zeta$ and accumulates in the cytoplasm, thereby blocking Notch4 gene regulation (54).

\section{NON-CANONICAL NOTCH SIGNALING}

Notch signaling can also occur in a non-canonical fashion that is independent of CSL and can be ligand dependent or independent 
(Figure 1) $(1,55)$. While canonical Notch signaling is well studied and crucial in various cellular processes as mentioned above, the known mechanisms of non-canonical signaling are limited but known to occur in cancer and some immune system cells (1). Non-canonical Notch pathways present an interesting new avenue of study and may reveal new targets for therapeutic intervention in the translational setting.

Notch signaling that occurs in the absence of CSL acts upon various cellular pathways that are involved in cancer and immune system responses. One such pathway is the $\mathrm{Wnt} / \beta$-catenin pathway. The Wnt $/ \beta$-catenin pathway is a conserved pathway that regulates cell pluripotency and cell fate decisions in development and postnatal life. Aberrant functions or mutations in $\beta$-catenin have been associated with a number of cancers and other human diseases. Non-canonical Notch signaling converges upon the Wnt/ $\beta$ catenin signaling pathway and results in an antagonistic interaction between Notch signaling and Wnt/ $\beta$-catenin $(6,55,56)$. This interaction disrupts the regulation of developmental and disease processes in a context (tissue)-dependent manner (55) and leads to negative regulation of Wnt signaling by altering the level of active $\beta$-catenin activity (3). High levels of membranebound Notch are associated with lower levels of active $\beta$-catenin, suggesting an inverse relationship between the two as well as a potential negative regulation of $\beta$-catenin by Notch (55). One example of this crosstalk is the loss of Notch 1 in the epidermis of mice, which results in activated Wnt $/ \beta$-catenin signaling and the formation of hyperplasia and cancer - both of which can be reversed by the introduction of exogenous NICD (57). In cervical cancer cells, Notch 1 activates NF-kB via IKK $\alpha$, which migrates to the nucleus in a Notch-dependent fashion (58); similarly, nuclear IKK $\alpha$ mediates the effect of Notch 1 in $\mathrm{ER}^{+}$breast cancer cells, whereby Notch1 activates ER $\alpha$-dependent transcription in an IKK $\alpha$-dependent fashion in the absence of estrogen (59).

In the immune system, non-canonical Notch signaling is involved in the activation and proliferation of $\mathrm{CD} 4^{+} \mathrm{T}$ cells as well as in the tumor-promoting effects of interleukin-6 (IL-6) $(1,60)$. These events rely on NF- $\mathrm{KB}$ and demonstrate crosstalk with other cellular pathways in the absence of canonical Notch signaling. Studies by the Osborne lab have established that even in the absence of CSL, activation and proliferation of $\mathrm{CD} 4^{+} \mathrm{T}$ cells does occur and requires Notch1 playing a major role in the signature CBM complex (CARMA1, MALT1, and BCL10) (61) by which $\mathrm{T}$ cells become activated through NF- $\mathrm{BB}$ (62). IL-6 has also been demonstrated as a Notch target gene in breast cancer cells, with the Notch-dependent activation of IL-6 reliant on IKK $\alpha / \beta$ function, but not on the canonical NF- $\kappa B$ signaling cascade (2). Furthermore, the Notch1 intracellular domain was shown to activate a non-canonical signaling cascade via mTORC2 and Akt as a means of transmitting extracellular nutrient sensing cues to promote cell survival $(4,63)$.

\section{NEUROENDOCRINE TUMORS - ENTEROPANCREATIC}

Carcinoids and NETs are a heterogeneous group of tumors that arise from the neuroendocrine cells of the GI tract, endocrine pancreas, and the lung (addressed separately below). Enteropancreatic NETs are slow growing tumors that can be associated with symptoms caused by peptide hormone release ("functional" NETs) and pose a significant threat due to high metastatic potential. The annual incidence of enteropancreatic NETs ranges from 2 to 5 per 100,000 patients in the United States and recent analyses suggest that this incidence will rise in the coming years $(56,64-66)$. The median overall survival (OS) for metastatic pancreatic and small bowel NETs is 24 and 56 months, respectively (65). Typically, enteropancreatic NETs are classified based on observable factors, such as anatomical site, histology, grade, level of differentiation, and hormone secretion, but due to the heterogeneous nature of the disease, this classification has led to confusion in both research and clinical settings. It is now recognized that NETs must be subdivided into pancreatic and non-pancreatic subgroups to reduce heterogeneity in clinical trials and patient care management. For a recent review on clinical management of NET patients, see Ref. (67). Progression-free survival (PFS), instead of OS, has become a frequently used endpoint in clinical trial design, and the degree of tumor differentiation has been noted as a key indicator of outcome. Differentiated tumors have a much better prognosis than poorly differentiated tumors, which can have a 5-year survival of less than $4 \%$ (66).

The only curative enteropancreatic NET treatment is surgery, and this is only effective if the tumors are removed prior to metastasis. Somatostatin analogs (SSAs), VEGF pathway inhibitors, mTOR inhibitors, and peptide receptor radionuclide therapy (PRRT) are currently in clinical practice and/or clinical trials, and have demonstrated moderate success. SSAs, such as octreotide, lanreotide, and pasireotide, have been used to control symptoms as a result of hormone hypersecretion (carcinoid syndrome) in these patients. More recently, SSAs have been noted to have antiproliferative effects on well or moderately differentiated NETs $(68,69)$, as reported for metastatic midgut NETs in the PROMID trial (70), and in pancreatic, midgut, or hindgut NETs in the CLARINET trial (71). Radiolabeled SSAs are also used in PRRT for a localized anticancer therapy in patients with inoperable or highly metastatic NETs. The first prospective, randomized trial, the NETTER-1 trial, is underway to compare radiolabeled

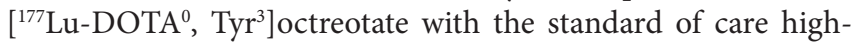
dose octreotide LAR in patients with inoperable, somatostatin receptor-positive metastatic midgut NETs (NCT01578239) with the primary endpoint of PFS. mTOR inhibitors, specifically everolimus or RAD001, showed efficacy the RADIANT-3 trial in patients with advanced pancreatic NETs when compared to placebo. Median PFS was 11 months compared to 4.6 months with placebo (72). The results of the RADIANT-3 trial led to FDA approval for everolimus for the treatment of advanced pancreatic NETs in 2011. Finally, the oral tyrosine kinase inhibitor sunitinib was studied in a prospective trial in patients with advanced, well-differentiated pancreatic NETs. PFS was 11.6 months in the sunitinib group compared to 5.5 months in the placebo arm (73). As with the RADIANT-3 trial, the increase in PFS resulted in FDA approval of sunitinib for advanced, well-differentiated pancreatic NETs. For a comprehensive review of all carcinoid and NET clinical trials, see Ref. (74). Given the heterogeneity 
of NETs, a better understanding of drug function, mechanism, and optimal patient group selection will guide future therapeutic strategies and clinical trials.

The genetics of NETs may also play a role in treatment development and selection. Genetic syndromes account for $15-20 \%$ of NETs, including multiple endocrine neoplasia type 1 and type 2 (MEN1 and MEN2), von Hippel-Lindau syndrome (VHL), neurofibromatosis type 1 (NF1), and tuberous sclerosis complex (TSC), but the remaining $80-85 \%$ of NET are considered sporadic. In an attempt to understand driving genetic mutations that result in pancreatic NETs, Jiao et al. (75) performed exome sequencing of 10 pancreatic NETs to identify mutated genes. This resulted in the identification of somatic mutations in a number of cancer genes, including MEN1, DAXX, ATRX, a number of genes involved in the mTOR pathway, and to a lesser extent TP53. A subsequent study by Banck et al. of 48 well-differentiated, small intestinal NETs (carcinoids) were analyzed by whole exome sequencing, and somatic mutations were identified in many cancer-associated genes, including FGFR2, MEN1, HOOK3, EZH2, MLF1, CARD11, VHL, NONO, SMAD 1, FANCD2, and BRAF (76). Analysis of 55 well-differentiated small intestinal NETs in a separate study identified 1230 genes with somatic variants (77), only 21 of which were in common with the Banck study. Further, upon comparison with the Jiao et al. study (75), only 17 genes with somatic mutations were in common with pancreatic NETs (77). These studies highlight the heterogeneity of NET tumors and reinforce that this group of tumors needs to be carefully studied, subgrouped, and analyzed to account for heterogeneity in terms of site of origin, level of differentiation, and underlying driver mutations. Interestingly enough and despite the somewhat disparate results, all of these studies have highlighted the putative role of chromatin remodeling, perhaps in concert with Notch signaling, in the etiology of enteropancreatic NETs.

\section{NEUROENDOCRINE TUMORS - PULMONARY}

Pulmonary NETs comprise a separate, diverse set of NETs that are classically described as falling on a continuum from welldifferentiated typical carcinoid (TC), to less differentiated atypical carcinoid (AC), to highly malignant and poorly differentiated small-cell lung carcinoma (SCLC), and large cell neuroendocrine carcinoma (LCNECs) (78). The distinction between these different tumor types is based on the WHO clinicopathological criteria of the mitotic index (number of mitoses per $2 \mathrm{~mm}^{2}$, usually equal to 10 high power fields). The mitotic index of TC is $<2, \mathrm{AC}$ is $2-10$, whereas SCLC and LCNECs have mitotic indices $>10$ (78). Immunohistochemistry using neuroendocrine markers, such as synaptophysin, chromogranin $\mathrm{A}$, and neural cell adhesion molecule (NCAM), are used to confirm neuroendocrine origin and define SCLC from non-SCLC. Although present at a much lower incidence than other pulmonary NETs, mixed pulmonary NETs can also form as a heterogeneous, combination of tumors consisting of mixtures of SCLC and LCNEC, or SCLC and nonSCLC with neuroendocrine differentiation (78).
The incidence of pulmonary NETs is low, roughly 1.57/100,000 individuals. TCs comprise 1-2\%, and ACs make up only $0.1-0.2 \%$ of pulmonary tumors, whereas SCLC and LCNET make up 20 and $1.6-3 \%$, respectively. The OS is $92-100 \%$ for TCs and $61-88 \%$ for ACs, whereas the higher grade SCLC and LCNET have a much poorer prognosis with OS as low as $5 \%$ (79). Treatment options for pulmonary NETs are limited. The only curative therapeutic option for TC and AC is surgery. These tumors do not respond well to chemotherapy and exhibit a response rate as low as $22 \%(80)$. SCLC and LCNEC are rarely treated with surgery because patients often present initially with advanced stage disease. The first-line treatment is chemotherapy (typically etoposide combined with carboplatin), with initial response rates as high as $90 \%$, but the majority of tumors recur and are resistant to further treatment (80). Studies in SCLC have evaluated the mTORC1 inhibitor everolimus in combination with standard of care chemotherapies cisplatin and etoposide, but dose-limiting toxicities and modest clinical efficacy suggest that this therapeutic combination is unlikely to be pursued (81). SSAs have been studied in a small number of clinical trials on pulmonary NETs, and the efficacy of these drugs on TC and AC is still under debate. The RADIANT-2 trial included enteropancreatic NETs as well as pulmonary TC and ACs treated with placebo plus octreotide LAR or everolimus plus octreotide LAR. Subgroup analyses from this study found a median PFS of 5.6 months for the few TC and AC patients who received only the octreotide LAR (82). A further trial is now open in Europe, called the LUNA trial which is a prospective, randomized, open-label, and three-arm design to study advanced lung (TC and AC) and thymic NET response to pasireotide LAR, everolimus, or both in combination (NCT01563354). In a phase II study in patients with relapsed or refractory SCLC, treatment with sunitinib was poorly tolerated and resulted in minimal gain in PFS (83). In addition to mTOR inhibitors, tyrosine kinase inhibitors, such as imatinib, have been studied in pulmonary NETs with disappointing results (84).

As with enteropancreatic NETs, the genetics of pulmonary NETs have also been explored in recent years. Genome-wide studies have been performed (85-88) to identify copy number alterations, point mutations, and changes in the transcriptome of SCLC. These studies identified copy number changes in the Myc family of oncogenes as well as potential driver mutations in genes such as TP53, RB1, CREBBP, EP300, MLL, and the SOX family. A separate study conducted whole-genome sequencing of 110 SCLC and identified biallelic inactivation of TP53, RB1, CREBBP, EP300, TP73, and RBL1/2, as well as inactivating mutations in Notch family genes in $25 \%$ of cases $(88,89)$. Exome sequencing of pancreatic and lung NET cell lines was reported earlier this year by Boora et al. (90). This study demonstrated a similar spectrum of mutant genes as those found in primary tumors, including TP53, RB1, EP300, and Notch, but also TSC2, GNAS, KDR, STK11, and APC. Interestingly enough, this analysis of lung and pancreatic NET cell lines did not identify DAXX, ATRX, or MEN1, and the authors suggested that the genetic signatures of these cell lines were not consistent with primary tumors and data from these cell lines should be interpreted with caution (90). 


\section{NOTCH SIGNALING AND NETs}

The NICDs of all Notch proteins are potentially oncogenic, and deregulated Notch signaling has been shown in many solid tumors, including breast $(18,91,92)$, cervical (93), endometrial (94), esophageal (95), gastric carcinoma (96), glioma (97), head and neck (98), hepatocellular (99), lung (100), medulloblastoma (101), melanoma (102), mesothelioma (7), ovarian (103), pancreatic (104), prostate (105), renal (106), and rhabdomyosarcoma (107). Additionally, Notch signaling is deregulated in hematological malignancies as well, including T-cell acute lymphoblastic leukemia (T-ALL) $(108,109)$, Hodgkin lymphomas (110), some acute myeloid leukemias (111), B-cell chronic lymphoid leukemia (112), and multiple myeloma (113). These observations suggest that dysregulated Notch signaling prevents differentiation and leads to malignancies in some of these cancers, while in others, the oncogenic role of Notch is likely due to inhibition of apoptosis.

The abundance of literature on the Notch signaling pathway is a testament to the complexity of this process in different cellular environments. This is especially true with a heterogeneous tumor group such as NETs. NETs remain significantly understudied with respect to molecular mechanisms of pathogenesis, and particularly Notch signaling. Mechanistically, Notch may contribute to carcinogenesis by inhibiting differentiation, promoting cellular proliferation, and/or inhibiting apoptosis, yet few studies have examined these endpoints in NETs. The relatively few studies published to date have focused primarily on the expression and function of Notchl. Contrary to the many tissue types discussed above, these studies suggest a tumor suppressive function for Notch 1 in neuroendocrine lineage cells. This is consistent with role of Notch in Drosophila neurogenesis, where it prevents neuroectodermal cell differentiation toward the neuronal lineage. In Drosophila embryos, loss of Notch results in a "neurogenic" phenotype, where differentiation toward the neuronal lineage is uncontrolled $(114,115)$.

It is plausible that loss of Notch1 signaling would allow NET cells to acquire or maintain a partially differentiated neuroendocrine phenotype while retaining the ability to proliferate. For example, recent studies $(11,12,116-119)$ report that Notch1 signaling is minimal or absent in pulmonary TC and AC and gut carcinoids. Yet these same cancers express high levels of human achaete-scute homolog 1 (hASH1), a basic helix-loop-helix transcription factor regulated by Notch signaling. Shida et al. propose that the aberrant expression of hASH1 may reflect the decreased differentiation and maturation of gastrointestinal NETs, suggesting that since hASH1 is not degraded temporospatially as it should be by Notch1-activated Hes1 and Hes5, the cells are arrested at an early stage of differentiation (119).

Studies in BON1 cells transiently overexpressing Notch1 NICD resulted in growth suppression, dose-dependent increases in Hes1, and a decrease in NET markers, confirming the tumor-suppressor function of Notch1 signaling in pancreatic NETs. In contrast, immunohistochemistry for Notch1, Hes1, Hey1, pIGF1R, and FGF2 antibodies on a tissue microarray of 120 well-differentiated NETs arising from the pancreas $(n=74)$, ilium $(n=31)$, and rectum $(n=15)$ demonstrated elevated Notch1 expression in $100 \%$ rectal, $34 \%$ of pancreatic, and $0 \%$ of ileal NETs, and Hes 1 expression in $64 \%$ of rectal, $10 \%$ of pancreatic, and $0 \%$ of ileal NETs
(120), exhibiting significant variability in Notch1 signaling across different tissue types. Furthermore, in the lung, Notch signaling can either promote or inhibit lung cancer, depending on tumor types. For example, Notch1 activation is thought to promote the growth of NSCLC but inhibit that of SCLC $(121,122)$. Studies on the expression of other Notch receptors and ligands in NETs are few. Notch 3 is known to play a tumor suppressive role in medullary thyroid carcinoma (123), but the role of Notch signaling in other NETs is understudied. Notch3 expression is decreased in SCLC compared to non-tumor lung tissue by immunohistochemistry, suggesting that Notch3 is involved in tumor suppression in SCLC (124). This may be the result of deregulated Notch functions in cell fate decisions that determine differentiation toward the epithelial Clara, ciliated, and pulmonary neuroendocrine cell lineages (125). In mouse models with allelic series deletion of Notch1-3, all three Notch receptors are required in an additive manner to regulate the abundance of neuroendocrine cells, whereas only contribution from Notch2 is required for Clara/ciliated cell development in the lung (126). There is limited information on Notch4 or the ligands involved in canonical Notch signaling in NETs. A comprehensive analysis of Notch expression patterns across all NET subtypes is required to fully understand the variability and redundant functions of Notch receptors and ligands.

Additional complexities arise in the form of transcriptional coactivators and corepressors that bind to NICD to regulate gene expression, as a growing body of evidence suggests that Notch behaves as an oncogene or a tumor suppressor depending on cellular context. For example, Notch1 is an oncogene in most systems, but in skin (127), some squamous epithelia (128), vasculature $(129,130)$, and potentially NETs, it behaves as a tumor suppressor (15). It is well established that the NICD binds to CSL, MAML, SKIP, and p300 to activate transcription of Notchresponsive genes via canonical Notch signaling. Similarly, the presence of varied corepressors in the absence of NICD also regulates transcription in specific ways that may be underappreciated. SMRT (28), SIRT (53), and histone lysine demethylase (LSD1) (131), among others [reviewed in Ref. (132)] have all been identified as corepressors of Notch/CSL signaling. Notch activator and repressor complexes have also been implicated in the epigenetic regulation of Notch signaling. Many Notch coactivators and corepressors are histone acetyltransferases, histone demethylases, histone methyltransferases, etc. and as a part of a complex with CSL, actively remodel the chromatin at Notch-responsive target genes, providing an additional layer of reversible regulation (34). Chromatin sites accessible to Notch NICDs are also influenced by other transcriptional regulators that can act as cofactors or inhibitors (133-135). A recent report by Liefke et al. (34) demonstrates that the histone demethylase KDM5A/RBP2 is a key component of the CSL repressor complex.

An additional layer of complexity is produced by paralogspecific effects. While in theory, all Notch receptors signal through CSL, they are not completely redundant, and there are instances in which their functions are not only independent but opposite. In NSCLC, Notch1 and Notch2 have opposite effects on Akt (136). Notch2 has been described as a tumor suppressor in breast cancer cell lines (137), while Notch1, 3, and 4 are uniformly oncogenic in the breast. The mechanism of these paralog-specific effects is 
unclear. They may involve "private" non-canonical signals, such as the inhibitory role of Notch4 on SMAD (138) or the stimulatory role of Notch1 on NF- $\mathrm{KB}$ (139). The oncogenic activity of Notch4 in the mouse mammary gland does not require CSL and is therefore completely or at least partially non-canonical (140). Alternatively, paralog-specific effects may be explained by quantitative differences in signal intensity. For instance, constitutively activating mutations in Notch1 and Notch2 are equally oncogenic in a subset of triple negative breast cancer (TNBC) (141), despite the fact that Notch2 has been described as a tumor suppressor in TNBC cell lines (137). In other words, variable signal intensity (the number of NICD molecules available as a result of overproduction or reduced degradation) may dictate different phenotypic consequences. This may be achieved perhaps by selective activation of chromatin sites with different affinity for Notch NICDs, similar to the well-known dose-dependent effects of $\mathrm{p} 53$, or by a combination of canonical and non-canonical effects that depend on NICD abundance. The role of paralog-specific effects has not been well characterized in NETs and is an area in need of further study.

Targeted therapies to modulate the Notch signaling pathway have been under development for several years, including neutralizing antibodies, decoy ligands, blocking peptides, natural compounds, and $\gamma$-secretase inhibitors [reviewed in Ref. (18)]. The Notch $2 / 3$ neutralizing antibody tarextumab inhibits tumor growth in mice not only in a variety of epithelial tumors but also in SCLC xenograft tumors (142). This suggests that either Notch2 or Notch3 inhibition can have therapeutic activity in SCLC cells or that non-cell autonomous effects on tumor stroma mediated by Notch2/3 inhibition are responsible for this effect. An interesting way of exploiting decreased Notch signaling therapeutically consists of targeting Notch ligands that are frequently overexpressed even in tumors with low canonical Notch signaling. An especially effective strategy for NETs was pioneered in SCLC, which frequently expresses high levels of DLL3. DLL3 can function as a Notch inhibitor, by retaining Notch receptors into the cytoplasm or by cis-inhibition. A DLL3 mAb conjugated with

\section{REFERENCES}

1. Ayaz F, Osborne BA. Non-canonical notch signaling in cancer and immunity. Front Oncol (2014) 4:345. doi:10.3389/fonc.2014.00345

2. Jin S, Mutvei AP, Chivukula IV, Andersson ER, Ramskold D, Sandberg R, et al. Non-canonical Notch signaling activates IL-6/JAK/STAT signaling in breast tumor cells and is controlled by $\mathrm{p} 53$ and IKKalpha/IKKbeta. Oncogene (2013) 32:4892-902. doi:10.1038/onc.2012.517

3. Kwon C, Cheng P, King IN, Andersen P, Shenje L, Nigam V, et al. Notch post-translationally regulates beta-catenin protein in stem and progenitor cells. Nat Cell Biol (2011) 13:1244-51. doi:10.1038/ncb2313

4. Perumalsamy LR, Nagala M, Banerjee P, Sarin A. A hierarchical cascade activated by non-canonical Notch signaling and the mTOR-Rictor complex regulates neglect-induced death in mammalian cells. Cell Death Differ (2009) 16:879-89. doi:10.1038/cdd.2009.20

5. Shin HM, Tilahun ME, Cho OH, Chandiran K, Kuksin CA, Keerthivasan S, et al. NOTCH1 can initiate NF-kappaB activation via cytosolic interactions with components of the T cell signalosome. Front Immunol (2014) 5:249. doi:10.3389/fimmu.2014.00249

6. Collu GM, Hidalgo-Sastre A, Brennan K. Wnt-Notch signalling crosstalk in development and disease. Cell Mol Life Sci (2014) 71:3553-67. doi:10.1007/ s00018-014-1644-x a toxic chemotherapeutic agent was highly effective in preclinical models of SCLC. However, the naked $\mathrm{mAb}$ had no therapeutic activity, suggesting that DLL3 inhibition alone is not a viable therapeutic strategy in SCLC (14).

\section{CONCLUSION}

The role of Notch signaling in NETs remains incompletely understood, but the careful and systematic study of Notch signaling in these tumors may reveal unique therapeutic possibilities by leveraging drugs in development or approved for other indications. Paralog-specific effects may be prominent in these tumors, and there is some preliminary evidence that Notch 1 and perhaps Notch3 act as a tumor suppressors in some of NETs but not in others. Further, expression data suggest that there may be significant heterogeneity among NETs in terms of expression of Notch receptors and target genes. The roles of Notch2, Notch4, and Notch ligands, if any, are understudied and remain unclear. It is known that DLL3 is expressed in some SCLC and is a useful targeting antigen for therapeutic immunotoxins, but the role of other ligands is unknown. The significant genetic heterogeneity of NETs suggests that individual molecular subtypes may have to be studied separately to dissect the roles of Notch signaling components and their potential therapeutic implications.

\section{AUTHOR CONTRIBUTIONS}

JC wrote the manuscript and generated the figures. CS wrote portions of the manuscript. LM wrote portions of the manuscript and edited the final version and figures.

\section{FUNDING}

This work was supported by the Louisiana State University Health Sciences Center School of Medicine, Department of Genetics (JC) and NIH/NCI grant \#P01CA166009 (LM).

7. Bocchetta M, Miele L, Pass HI, Carbone M. Notch-1 induction, a novel activity of SV40 required for growth of SV40-transformed human mesothelial cells. Oncogene (2003) 22:81-9. doi:10.1038/sj.onc.1206097

8. Carter Y, Jaskula-Sztul R, Chen H, Mazeh H. Signaling pathways as specific pharmacologic targets for neuroendocrine tumor therapy: RET, PI3K, MEK, growth factors, and Notch. Neuroendocrinology (2013) 97:57-66. doi:10.1159/000335136

9. Hassan WA, Yoshida R, Kudoh S, Hasegawa K, Niimori-Kita K, Ito T. Notch1 controls cell invasion and metastasis in small cell lung carcinoma cell lines. Lung Cancer (2014) 86:304-10. doi:10.1016/j.lungcan.2014.10.007

10. Krausch M, Kroepil F, Lehwald N, Lachenmayer A, Schott M, Anlauf M, et al. Notch 1 tumor expression is lacking in highly proliferative pancreatic neuroendocrine tumors. Endocrine (2013) 44:182-6. doi:10.1007/ s12020-012-9850-5

11. Kunnimalaiyaan M, Chen H. Tumor suppressor role of Notch-1 signaling in neuroendocrine tumors. Oncologist (2007) 12:535-42. doi:10.1634/ theoncologist.12-5-535

12. Kunnimalaiyaan M, Yan S, Wong F, Zhang YW, Chen H. Hairy enhancer of split-1 (HES-1), a Notch1 effector, inhibits the growth of carcinoid tumor cells. Surgery (2005) 138:1137-42. doi:10.1016/j.surg.2005.05.027

13. Meder L, Konig K, Ozretic L, Schultheis AM, Ueckeroth F, Ade CP, et al. NOTCH, ASCL1, p53 and RB alterations define an alternative pathway 
driving neuroendocrine and small cell lung carcinomas. Int J Cancer (2016) 138:927-38. doi:10.1002/ijc.29835

14. Saunders LR, Bankovich AJ, Anderson WC, Aujay MA, Bheddah S, Black $\mathrm{K}$, et al. A DLL3-targeted antibody-drug conjugate eradicates high-grade pulmonary neuroendocrine tumor-initiating cells in vivo. Sci Transl Med (2015) 7:302ra136. doi:10.1126/scitranslmed.aac9459

15. Andersson ER, Lendahl U. Therapeutic modulation of Notch signalling - are we there yet? Nat Rev Drug Discov (2014) 13:357-78. doi:10.1038/nrd4252

16. Chikara S, Reindl KM. Notch signaling: a hero or villain in the war against cancer? Transl Lung Cancer Res (2013) 2:449-51. doi:10.3978/j. issn.2218-6751.2013.10.15

17. D'Souza B, Miyamoto A, Weinmaster G. The many facets of Notch ligands. Oncogene (2008) 27:5148-67. doi:10.1038/onc.2008.229

18. Espinoza I, Miele L. Notch inhibitors for cancer treatment. Pharmacol Ther (2013) 139:95-110. doi:10.1016/j.pharmthera.2013.02.003

19. Heuss SF, Ndiaye-Lobry D, Six EM, Israel A, Logeat F. The intracellular region of Notch ligands Dll1 and Dll3 regulates their trafficking and signaling activity. Proc Natl Acad Sci U S A (2008) 105:11212-7. doi:10.1073/pnas.0800695105

20. Wang H, Zang C, Taing L, Arnett KL, Wong YJ, Pear WS, et al. NOTCH1-RBPJ complexes drive target gene expression through dynamic interactions with superenhancers. Proc Natl Acad Sci U S A (2014) 111:705-10. doi:10.1073/ pnas. 1315023111

21. Wu L, Aster JC, Blacklow SC, Lake R, Artavanis-Tsakonas S, Griffin JD. MAML1, a human homologue of Drosophila mastermind, is a transcriptional co-activator for NOTCH receptors. Nat Genet (2000) 26:484-9. doi:10.1038/82644

22. Jeffries S, Robbins DJ, Capobianco AJ. Characterization of a high-molecular-weight Notch complex in the nucleus of Notch(ic)-transformed RKE cells and in a human T-cell leukemia cell line. Mol Cell Biol (2002) 22:3927-41. doi:10.1128/MCB.22.11.3927-3941.2002

23. Kovall RA, Blacklow SC. Mechanistic insights into Notch receptor signaling from structural and biochemical studies. Curr Top Dev Biol (2010) 92:31-71. doi:10.1016/S0070-2153(10)92002-4

24. Vasquez-Del Carpio R, Kaplan FM, Weaver KL, VanWye JD, Alves-Guerra MC, Robbins DJ, et al. Assembly of a Notch transcriptional activation complex requires multimerization. Mol Cell Biol (2011) 31:1396-408. doi:10.1128/MCB.00360-10

25. Wallberg AE, Pedersen K, Lendahl U, Roeder RG. p300 and PCAF act cooperatively to mediate transcriptional activation from chromatin templates by notch intracellular domains in vitro. Mol Cell Biol (2002) 22:7812-9. doi:10.1128/MCB.22.22.7812-7819.2002

26. Kurooka H, Honjo T. Functional interaction between the mouse notch1 intracellular region and histone acetyltransferases PCAF and GCN5.J Biol Chem (2000) 275:17211-20. doi:10.1074/jbc.M000909200

27. Lai EC. Keeping a good pathway down: transcriptional repression of Notch pathway target genes by CSL proteins. EMBO Rep (2002) 3:840-5. doi:10.1093/embo-reports/kvf170

28. Kao HY, Ordentlich P, Koyano-Nakagawa N, Tang Z, Downes M, Kintner $\mathrm{CR}$, et al. A histone deacetylase corepressor complex regulates the Notch signal transduction pathway. Genes Dev (1998) 12:2269-77. doi:10.1101/ gad.12.15.2269

29. Oswald F, Kostezka U, Astrahantseff K, Bourteele S, Dillinger K, Zechner $\mathrm{U}$, et al. SHARP is a novel component of the Notch/RBP-Jkappa signalling pathway. EMBO J (2002) 21:5417-26. doi:10.1093/emboj/cdf549

30. Oswald F, Winkler M, Cao Y, Astrahantseff K, Bourteele S, Knochel W, et al. RBP-Jkappa/SHARP recruits CtIP/CtBP corepressors to silence Notch target genes. Mol Cell Biol (2005) 25:10379-90. doi:10.1128/ MCB.25.23.10379-10390.2005

31. Hsieh JJ, Zhou S, Chen L, Young DB, Hayward SD. CIR, a corepressor linking the DNA binding factor CBF1 to the histone deacetylase complex. Proc Natl Acad Sci U S A (1999) 96:23-8. doi:10.1073/pnas.96.1.23

32. King IN, Kathiriya IS, Murakami M, Nakagawa M, Gardner KA, Srivastava $D$, et al. Hrt and Hes negatively regulate Notch signaling through interactions with RBP-Jkappa. Biochem Biophys Res Commun (2006) 345:446-52. doi:10.1016/j.bbrc.2006.04.097

33. Kim MY, Ann EJ, Mo JS, Dajas-Bailador F, Seo MS, Hong JA, et al. JIP1 binding to RBP-Jk mediates cross-talk between the Notch1 and JIP1-JNK signaling pathway. Cell Death Differ (2010) 17:1728-38. doi:10.1038/cdd.2010.50
34. Liefke R, Oswald F, Alvarado C, Ferres-Marco D, Mittler G, Rodriguez P, et al. Histone demethylase KDM5A is an integral part of the core Notch-RBP-J repressor complex. Genes Dev (2010) 24:590-601. doi:10.1101/gad.563210

35. Fryer CJ, White JB, Jones KA. Mastermind recruits $\mathrm{CycC}$ :CDK8 to phosphorylate the Notch ICD and coordinate activation with turnover. Mol Cell (2004) 16:509-20. doi:10.1016/j.molcel.2004.10.014

36. Oberg C, Li J, Pauley A, Wolf E, Gurney M, Lendahl U. The Notch intracellular domain is ubiquitinated and negatively regulated by the mammalian Sel-10 homolog. J Biol Chem (2001) 276:35847-53. doi:10.1074/jbc.M103992200

37. Wu G, Lyapina S, Das I, Li J, Gurney M, Pauley A, et al. SEL-10 is an inhibitor of notch signaling that targets notch for ubiquitin-mediated protein degradation. Mol Cell Biol (2001) 21:7403-15. doi:10.1128/MCB.21.21.7403-7415.2001

38. Ranganathan P, Vasquez-Del Carpio R, Kaplan FM, Wang H, Gupta A, VanWye JD, et al. Hierarchical phosphorylation within the ankyrin repeat domain defines a phosphoregulatory loop that regulates Notch transcriptional activity. J Biol Chem (2011) 286:28844-57. doi:10.1074/jbc.M111.243600

39. Foltz DR, Santiago MC, Berechid BE, Nye JS. Glycogen synthase kinase3beta modulates notch signaling and stability. Curr Biol (2002) 12:1006-11. doi:10.1016/S0960-9822(02)00888-6

40. Moloney DJ, Panin VM, Johnston SH, Chen J, Shao L, Wilson R, et al. Fringe is a glycosyltransferase that modifies Notch. Nature (2000) 406:369-75. doi: $10.1038 / 35019000$

41. Moloney DJ, Shair LH, Lu FM, Xia J, Locke R, Matta KL, et al. Mammalian Notch1 is modified with two unusual forms of O-linked glycosylation found on epidermal growth factor-like modules. J Biol Chem (2000) 275:9604-11. doi:10.1074/jbc.275.13.9604

42. Okajima T, Xu A, Irvine KD. Modulation of notch-ligand binding by protein O-fucosyltransferase 1 and fringe. J Biol Chem (2003) 278:42340-5. doi:10.1074/jbc.M308687200

43. Bruckner K, Perez L, Clausen H, Cohen S. Glycosyltransferase activity of fringe modulates Notch-Delta interactions. Nature (2000) 406:411-5. doi:10.1038/35019075

44. Panin VM, Papayannopoulos V, Wilson R, Irvine KD. Fringe modulates Notch-ligand interactions. Nature (1997) 387:908-12. doi:10.1038/43191

45. Acar M, Jafar-Nejad H, Takeuchi H, Rajan A, Ibrani D, Rana NA, et al. Rumi is a CAP10 domain glycosyltransferase that modifies Notch and is required for Notch signaling. Cell (2008) 132:247-58. doi:10.1016/j. cell.2007.12.016

46. Lee TV, Sethi MK, Leonardi J, Rana NA, Buettner FF, Haltiwanger RS, et al. Negative regulation of notch signaling by xylose. PLoS Genet (2013) 9:e1003547. doi:10.1371/journal.pgen.1003547

47. Rana NA, Haltiwanger RS. Fringe benefits: functional and structural impacts of O-glycosylation on the extracellular domain of Notch receptors. Curr Opin Struct Biol (2011) 21:583-9. doi:10.1016/j.sbi.2011.08.008

48. Sethi MK, Buettner FF, Ashikov A, Krylov VB, Takeuchi H, Nifantiev NE, et al. Molecular cloning of a xylosyltransferase that transfers the second xylose to O-glucosylated epidermal growth factor repeats of notch. J Biol Chem (2012) 287:2739-48. doi:10.1074/jbc.M111.302406

49. Palermo R, Checquolo S, Giovenco A, Grazioli P, Kumar V, Campese AF, et al. Acetylation controls Notch3 stability and function in T-cell leukemia. Oncogene (2012) 31:3807-17. doi:10.1038/onc.2011.533

50. Popko-Scibor AE, Lindberg MJ, Hansson ML, Holmlund T, Wallberg AE. Ubiquitination of Notch1 is regulated by MAML1-mediated p300 acetylation of Notch1. Biochem Biophys Res Commun (2011) 416:300-6. doi:10.1016/j. bbrc.2011.11.030

51. Rustighi A, Tiberi L, Soldano A, Napoli M, Nuciforo P, Rosato A, et al. The prolyl-isomerase Pin1 is a Notch1 target that enhances Notch1 activation in cancer. Nat Cell Biol (2009) 11:133-42. doi:10.1038/ncb1822

52. Guarani V, Deflorian G, Franco CA, Kruger M, Phng LK, Bentley K, et al. Acetylation-dependent regulation of endothelial Notch signalling by the SIRT1 deacetylase. Nature (2011) 473:234-8. doi:10.1038/nature09917

53. Mulligan P, Yang F, Di Stefano L, Ji JY, Ouyang J, Nishikawa JL, et al. A SIRT1-LSD1 corepressor complex regulates Notch target gene expression and development. Mol Cell (2011) 42:689-99. doi:10.1016/j. molcel.2011.04.020

54. Ramakrishnan G, Davaakhuu G, Chung WC, Zhu H, Rana A, Filipovic A, et al. AKT and 14-3-3 regulate Notch4 nuclear localization. Sci Rep (2015) 5:8782. doi: $10.1038 /$ srep08782 
55. Andersen P, Uosaki H, Shenje LT, Kwon C. Non-canonical Notch signaling: emerging role and mechanism. Trends Cell Biol (2012) 22:257-65. doi:10.1016/j.tcb.2012.02.003

56. Lawrence B, Gustafsson BI, Chan A, Svejda B, Kidd M, Modlin IM. The epidemiology of gastroenteropancreatic neuroendocrine tumors. Endocrinol Metab Clin North Am (2011) 40:1-18, vii. doi:10.1016/j.ecl.2010.12.005

57. Nicolas M, Wolfer A, Raj K, Kummer JA, Mill P, van Noort M, et al. Notch1 functions as a tumor suppressor in mouse skin. Nat Genet (2003) 33:416-21. doi:10.1038/ng1099

58. Song LL, Peng Y, Yun J, Rizzo P, Chaturvedi V, Weijzen S, et al. Notch-1 associates with IKKalpha and regulates IKK activity in cervical cancer cells. Oncogene (2008) 27:5833-44. doi:10.1038/onc.2008.190

59. Hao L, Rizzo P, Osipo C, Pannuti A, Wyatt D, Cheung LW, et al. Notch-1 activates estrogen receptor-alpha-dependent transcription via IKKalpha in breast cancer cells. Oncogene (2010) 29:201-13. doi:10.1038/onc.2009.323

60. Dongre A, Surampudi L, Lawlor RG, Fauq AH, Miele L, Golde TE, et al. Noncanonical Notch signaling drives activation and differentiation of peripheral CD4(+) T cells. Front Immunol (2014) 5:54. doi:10.3389/fimmu.2014.00054

61. Thome M. CARMA1, BCL-10 and MALT1 in lymphocyte development and activation. Nat Rev Immunol (2004) 4:348-59. doi:10.1038/nri1352

62. Minter LM, Osborne BA. Canonical and non-canonical Notch signaling in CD4(+) T cells. Curr Top Microbiol Immunol (2012) 360:99-114. doi: 10.1007/82_2012_233

63. Meurette O, Stylianou S, Rock R, Collu GM, Gilmore AP, Brennan K. Notch activation induces Akt signaling via an autocrine loop to prevent apoptosis in breast epithelial cells. Cancer Res (2009) 69:5015-22. doi:10.1158/0008-5472. CAN-08-3478

64. Garcia-Carbonero R, Capdevila J, Crespo-Herrero G, Diaz-Perez JA, Martinez Del Prado MP, Alonso Orduna V, et al. Incidence, patterns of care and prognostic factors for outcome of gastroenteropancreatic neuroendocrine tumors (GEP-NETs): results from the National Cancer Registry of Spain (RGETNE). Ann Oncol (2010) 21:1794-803. doi:10.1093/annonc/mdq022

65. Mocellin S, Nitti D. Gastrointestinal carcinoid: epidemiological and survival evidence from a large population-based study $(\mathrm{n}=25531)$. Ann Oncol (2013) 24:3040-4. doi:10.1093/annonc/mdt377

66. Yao JC, Hassan M, Phan A, Dagohoy C, Leary C, Mares JE, et al. One hundred years after "carcinoid": epidemiology of and prognostic factors for neuroendocrine tumors in 35,825 cases in the United States. J Clin Oncol (2008) 26:3063-72. doi:10.1200/JCO.2007.15.4377

67. Strosberg J. Neuroendocrine tumours of the small intestine. Best practice \& research. Clin Gastroenterol (2012) 26:755-73. doi:10.1016/j.bpg.2012.12.002

68. Susini C, Buscail L. Rationale for the use of somatostatin analogs as antitumor agents. Ann Oncol (2006) 17:1733-42. doi:10.1093/annonc/mdl105

69. Cives M, Strosberg J. The expanding role of somatostatin analogs in gastroenteropancreatic and lung neuroendocrine tumors. Drugs (2015) 75:847-58. doi:10.1007/s40265-015-0397-7

70. Rinke A, Muller HH, Schade-Brittinger C, Klose KJ, Barth P, Wied M, et al. Placebo-controlled, double-blind, prospective, randomized study on the effect of octreotide LAR in the control of tumor growth in patients with metastatic neuroendocrine midgut tumors: a report from the PROMID Study Group. J Clin Oncol (2009) 27:4656-63. doi:10.1200/JCO.2009.22.8510

71. Caplin ME, Pavel M, Cwikla JB, Phan AT, Raderer M, Sedlackova E, et al. Lanreotide in metastatic enteropancreatic neuroendocrine tumors. $N$ Engl $J$ Med (2014) 371:224-33. doi:10.1056/NEJMoa1316158

72. Yao JC, Shah MH, Ito T, Bohas CL, Wolin EM, Van Cutsem E, et al. Everolimus for advanced pancreatic neuroendocrine tumors. $N$ Engl J Med (2011) 364:514-23. doi:10.1056/NEJMoa1009290

73. Raymond E, Dahan L, Raoul JL, Bang YJ, Borbath I, Lombard-Bohas C, et al. Sunitinib malate for the treatment of pancreatic neuroendocrine tumors. $N$ Engl J Med (2011) 364:501-13. doi:10.1056/NEJMoa1003825

74. Kunz PL. Carcinoid and neuroendocrine tumors: building on success. J Clin Oncol (2015) 33:1855-63. doi:10.1200/JCO.2014.60.2532

75. Jiao Y, Shi C, Edil BH, de Wilde RF, Klimstra DS, Maitra A, et al. DAXX/ ATRX, MEN1, and mTOR pathway genes are frequently altered in pancreatic neuroendocrine tumors. Science (2011) 331:1199-203. doi:10.1126/ science. 1200609

76. Banck MS, Kanwar R, Kulkarni AA, Boora GK, Metge F, Kipp BR, et al. The genomic landscape of small intestine neuroendocrine tumors. J Clin Invest (2013) 123:2502-8. doi:10.1172/JCI67963
77. Francis JM, Kiezun A, Ramos AH, Serra S, Pedamallu CS, Qian ZR, et al. Somatic mutation of CDKN1B in small intestine neuroendocrine tumors. Nat Genet (2013) 45:1483-6. doi:10.1038/ng.2821

78. Swarts DR, Ramaekers FC, Speel EJ. Molecular and cellular biology of neuroendocrine lung tumors: evidence for separate biological entities. Biochim Biophys Acta (2012) 1826:255-71. doi:10.1016/j.bbcan.2012.05.001

79. Travis WD. Advances in neuroendocrine lung tumors. Ann Oncol (2010) 7:vii65-71. doi:10.1093/annonc/mdq380

80. Detterbeck FC. Management of carcinoid tumors. Ann Thorac Surg (2010) 89:998-1005. doi:10.1016/j.athoracsur.2009.07.097

81. Besse B, Heist RS, Papadmitrakopoulou VA, Camidge DR, Beck JT, Schmid $\mathrm{P}$, et al. A phase Ib dose-escalation study of everolimus combined with cisplatin and etoposide as first-line therapy in patients with extensive-stage small-cell lung cancer. Ann Oncol (2014) 25:505-11. doi:10.1093/annonc/ mdt535

82. Pavel ME, Hainsworth JD, Baudin E, Peeters M, Horsch D, Winkler RE, et al. Everolimus plus octreotide long-acting repeatable for the treatment of advanced neuroendocrine tumours associated with carcinoid syndrome (RADIANT-2): a randomised, placebo-controlled, phase 3 study. Lancet (2011) 378:2005-12. doi:10.1016/S0140-6736(11)61742-X

83. Han JY, Kim HY, Lim KY, Han JH, Lee YJ, Kwak MH, et al. A phase II study of sunitinib in patients with relapsed or refractory small cell lung cancer. Lung Cancer (2013) 79:137-42. doi:10.1016/j.lungcan.2012.09.019

84. Johnson BE, Fischer T, Fischer B, Dunlop D, Rischin D, Silberman S, et al. Phase II study of imatinib in patients with small cell lung cancer. Clin Cancer Res (2003) 9:5880-7.

85. Iwakawa R, Takenaka M, Kohno T, Shimada Y, Totoki Y, Shibata T, et al. Genome-wide identification of genes with amplification and/or fusion in small cell lung cancer. Genes Chromosomes Cancer (2013) 52:802-16. doi: $10.1002 /$ gcc. 22076

86. Peifer M, Fernandez-Cuesta L, Sos ML, George J, Seidel D, Kasper LH, et al. Integrative genome analyses identify key somatic driver mutations of smallcell lung cancer. Nat Genet (2012) 44:1104-10. doi:10.1038/ng.2396

87. Rudin CM, Durinck S, Stawiski EW, Poirier JT, Modrusan Z, Shames DS, et al. Comprehensive genomic analysis identifies SOX2 as a frequently amplified gene in small-cell lung cancer. Nat Genet (2012) 44:1111-6. doi:10.1038/ ng. 2405

88. Fernandez-Cuesta L, Peifer M, Lu X, Sun R, Ozretic L, Seidel D, et al. Frequent mutations in chromatin-remodelling genes in pulmonary carcinoids. Nat Commun (2014) 5:3518. doi:10.1038/ncomms4518

89. George J, Lim JS, Jang SJ, Cun Y, Ozretic L, Kong G, et al. Comprehensive genomic profiles of small cell lung cancer. Nature (2015) 524:47-53. doi:10.1038/nature14664

90. Boora GK, Kanwar R, Kulkarni AA, Pleticha J, Ames M, Schroth G, et al. Exome-level comparison of primary well-differentiated neuroendocrine tumors and their cell lines. Cancer Genet (2015) 208:374-81. doi:10.1016/j. cancergen.2015.04.002

91. Espinoza I, Miele L. Deadly crosstalk: Notch signaling at the intersection of EMT and cancer stem cells. Cancer Lett (2013) 341:41-5. doi:10.1016/j. canlet.2013.08.027

92. Espinoza I, Pochampally R, Xing F, Watabe K, Miele L. Notch signaling: targeting cancer stem cells and epithelial-to-mesenchymal transition. Onco Targets Ther (2013) 6:1249-59. doi:10.2147/OTT.S36162

93. Zagouras P, Stifani S, Blaumueller CM, Carcangiu ML, Artavanis-Tsakonas S. Alterations in Notch signaling in neoplastic lesions of the human cervix. Proc Natl Acad Sci U S A (1995) 92:6414-8. doi:10.1073/pnas.92.14.6414

94. Suzuki T, Aoki D, Susumu N, Udagawa Y, Nozawa S. Imbalanced expression of TAN-1 and human Notch4 in endometrial cancers. Int J Oncol (2000) 17:1131-9. doi: 10.3892/ijo.17.6.1131

95. Subramaniam D, Ponnurangam S, Ramamoorthy P, Standing D, Battafarano RJ, Anant $S$, et al. Curcumin induces cell death in esophageal cancer cells through modulating Notch signaling. PLoS One (2012) 7:e30590. doi:10.1371/ journal.pone. 0030590

96. Yeh TS, Wu CW, Hsu KW, Liao WJ, Yang MC, Li AF, et al. The activated Notch1 signal pathway is associated with gastric cancer progression through cyclooxygenase-2. Cancer Res (2009) 69:5039-48. doi:10.1158/0008-5472. CAN-08-4021

97. Purow BW, Haque RM, Noel MW, Su Q, Burdick MJ, Lee J, et al. Expression of Notch-1 and its ligands, Delta-like-1 and Jagged-1, is critical for glioma cell 
survival and proliferation. Cancer Res (2005) 65:2353-63. doi:10.1158/00085472.CAN-04-1890

98. Leethanakul C, Patel V, Gillespie J, Pallente M, Ensley JF, Koontongkaew $S$, et al. Distinct pattern of expression of differentiation and growth-related genes in squamous cell carcinomas of the head and neck revealed by the use of laser capture microdissection and cDNA arrays. Oncogene (2000) 19:3220-4. doi:10.1038/sj.onc. 1203703

99. Wang M, Xue L, Cao Q, Lin Y, Ding Y, Yang P, et al. Expression of Notch1, Jagged 1 and beta-catenin and their clinicopathological significance in hepatocellular carcinoma. Neoplasma (2009) 56:533-41. doi:10.4149/ neo_2009_06_533

100. Dang TP, Gazdar AF, Virmani AK, Sepetavec T, Hande KR, Minna JD, et al. Chromosome 19 translocation, overexpression of Notch3, and human lung cancer. J Natl Cancer Inst (2000) 92:1355-7. doi:10.1093/jnci/92.16.1355

101. Fan X, Mikolaenko I, Elhassan I, Ni X, Wang Y, Ball D, et al. Notch1 and notch2 have opposite effects on embryonal brain tumor growth. Cancer Res (2004) 64:7787-93. doi:10.1158/0008-5472.CAN-04-1446

102. Balint K, Xiao M, Pinnix CC, Soma A, Veres I, Juhasz I, et al. Activation of Notch1 signaling is required for beta-catenin-mediated human primary melanoma progression. JClin Invest (2005) 115:3166-76. doi:10.1172/ JCI25001

103. McAuliffe SM, Morgan SL, Wyant GA, Tran LT, Muto KW, Chen YS, et al. Targeting Notch, a key pathway for ovarian cancer stem cells, sensitizes tumors to platinum therapy. Proc Natl Acad Sci U S A (2012) 109:E2939-48. doi:10.1073/pnas.1206400109

104. Miyamoto Y, Maitra A, Ghosh B, Zechner U, Argani P, Iacobuzio-Donahue $\mathrm{CA}$, et al. Notch mediates TGF alpha-induced changes in epithelial differentiation during pancreatic tumorigenesis. Cancer Cell (2003) 3:565-76. doi:10.1016/S1535-6108(03)00140-5

105. Santagata S, Demichelis F, Riva A, Varambally S, Hofer MD, Kutok JL, et al. JAGGED1 expression is associated with prostate cancer metastasis and recurrence. Cancer Res (2004) 64:6854-7. doi:10.1158/0008-5472. CAN-04-2500

106. Rae FK, Stephenson SA, Nicol DL, Clements JA. Novel association of a diverse range of genes with renal cell carcinoma as identified by differential display. Int JCancer (2000) 88:726-32. doi:10.1002/1097-0215(20001201)88:5<726::AID-IJC7>3.0.CO;2-H

107. Raimondi L, Ciarapica R, De Salvo M, Verginelli F, Gueguen M, Martini C, et al. Inhibition of Notch3 signalling induces rhabdomyosarcoma cell differentiation promoting $\mathrm{p} 38$ phosphorylation and p21(Cip1) expression and hampers tumour cell growth in vitro and in vivo. Cell Death Differ (2012) 19:871-81. doi:10.1038/cdd.2011.171

108. Ellisen LW, Bird J, West DC, Soreng AL, Reynolds TC, Smith SD, et al. TAN-1, the human homolog of the Drosophila notch gene, is broken by chromosomal translocations in T lymphoblastic neoplasms. Cell (1991) 66:649-61. doi:10.1016/0092-8674(91)90111-B

109. Weng AP, Ferrando AA, Lee W, Morris JP, Silverman LB, Sanchez-Irizarry C, et al. Activating mutations of NOTCH1 in human T cell acute lymphoblastic leukemia. Science (2004) 306:269-71. doi:10.1126/science.1102160

110. Jundt F, Anagnostopoulos I, Forster R, Mathas S, Stein H, Dorken B. Activated Notch1 signaling promotes tumor cell proliferation and survival in Hodgkin and anaplastic large cell lymphoma. Blood (2002) 99:3398-403. doi:10.1182/ blood.V99.9.3398

111. Tohda S, Nara N. Expression of Notch1 and Jagged1 proteins in acute myeloid leukemia cells. Leuk Lymphoma (2001) 42:467-72. doi: $10.3109 / 10428190109064603$

112. Hajdu M, Kopper L, Sebestyen A. Notch-regulation upon Dll4stimulation of TGFb-induced apoptosis and gene expression in human B-cell non-Hodgkin lymphomas. Scand JImmunol (2010) 71:29-37. doi:10.1111/j.1365-3083.2009.02346.x

113. Jundt F, Probsting KS, Anagnostopoulos I, Muehlinghaus G, Chatterjee $\mathrm{M}$, Mathas $\mathrm{S}$, et al. Jagged1-induced Notch signaling drives proliferation of multiple myeloma cells. Blood (2004) 103:3511-5. doi:10.1182/ blood-2003-07-2254

114. Louvi A, Artavanis-Tsakonas S. Notch signalling in vertebrate neural development. Nat Rev Neurosci (2006) 7:93-102. doi:10.1038/nrn1847

115. Artavanis-Tsakonas S, Rand MD, Lake RJ. Notch signaling: cell fate control and signal integration in development. Science (1999) 284:770-6. doi:10.1126/science.284.5415.770
116. Kunnimalaiyaan M, Traeger K, Chen H. Conservation of the Notch1 signaling pathway in gastrointestinal carcinoid cells. Am J Physiol Gastrointest Liver Physiol (2005) 289:G636-42. doi:10.1152/ajpgi.00146.2005

117. Kunnimalaiyaan M, Vaccaro AM, Ndiaye MA, Chen H. Overexpression of the NOTCH1 intracellular domain inhibits cell proliferation and alters the neuroendocrine phenotype of medullary thyroid cancer cells. J Biol Chem (2006) 281:39819-30. doi:10.1074/jbc.M603578200

118. Nakakura EK, Sriuranpong VR, Kunnimalaiyaan M, Hsiao EC, Schuebel KE, Borges MW, et al. Regulation of neuroendocrine differentiation in gastrointestinal carcinoid tumor cells by notch signaling. J Clin Endocrinol Metab (2005) 90:4350-6. doi:10.1210/jc.2005-0540

119. Shida T, Furuya M, Nikaido T, Hasegawa M, Koda K, Oda K, et al. Sonic Hedgehog-Gli1 signaling pathway might become an effective therapeutic target in gastrointestinal neuroendocrine carcinomas. Cancer Biol Ther (2006) 5:1530-8. doi:10.4161/cbt.5.11.3458

120. Wang H, Chen Y, Fernandez-Del Castillo C, Yilmaz O, Deshpande V. Heterogeneity in signaling pathways of gastroenteropancreatic neuroendocrine tumors: a critical look at notch signaling pathway. Mod Pathol (2013) 26:139-47. doi:10.1038/modpathol.2012.143

121. Eliasz S, Liang S, Chen Y, De Marco MA, Machek O, Skucha S, et al. Notch-1 stimulates survival of lung adenocarcinoma cells during hypoxia by activating the IGF-1R pathway. Oncogene (2010) 29:2488-98. doi:10.1038/onc.2010.7

122. Sriuranpong V, Borges MW, Ravi RK, Arnold DR, Nelkin BD, Baylin SB, et al. Notch signaling induces cell cycle arrest in small cell lung cancer cells. Cancer Res (2001) 61:3200-5.

123. Jaskula-Sztul R, Eide J, Tesfazghi S, Dammalapati A, Harrison AD, Yu XM, et al. Tumor-suppressor role of Notch3 in medullary thyroid carcinoma revealed by genetic and pharmacological induction. Mol Cancer Ther (2015) 14:499-512. doi:10.1158/1535-7163.MCT-14-0073

124. Zhou M, Jin WY, Fan ZW, Han RC. Analysis of the expression of the Notch3 receptor protein in adult lung cancer. Oncol Lett (2013) 5:499-504. doi: 10.3892/ol.2012.1033

125. Ito T, Udaka N, Yazawa T, Okudela K, Hayashi H, Sudo T, et al. Basic helixloop-helix transcription factors regulate the neuroendocrine differentiation of fetal mouse pulmonary epithelium. Development (2000) 127:3913-21.

126. Morimoto M, Nishinakamura R, Saga Y, Kopan R. Different assemblies of Notch receptors coordinate the distribution of the major bronchial Clara, ciliated and neuroendocrine cells. Development (2012) 139:4365-73. doi: $10.1242 / \mathrm{dev} .083840$

127. Massi D, Panelos J. Notch signaling and the developing skin epidermis. $A d v$ Exp Med Biol (2012) 727:131-41. doi:10.1007/978-1-4614-0899-4_10

128. Agrawal N, Frederick MJ, Pickering CR, Bettegowda C, Chang K, Li RJ, et al. Exome sequencing of head and neck squamous cell carcinoma reveals inactivating mutations in NOTCH1. Science (2011) 333:1154-7. doi:10.1126/ science. 1206923

129. Liu Z, Turkoz A, Jackson EN, Corbo JC, Engelbach JA, Garbow JR, et al. Notch1 loss of heterozygosity causes vascular tumors and lethal hemorrhage in mice. J Clin Invest (2011) 121:800-8. doi:10.1172/JCI43114

130. Li X, Zhang X, Leathers R, Makino A, Huang C, Parsa P, et al. Notch3 signaling promotes the development of pulmonary arterial hypertension. Nat Med (2009) 15:1289-97. doi:10.1038/nm.2021

131. Wang J, Scully K, Zhu X, Cai L, Zhang J, Prefontaine GG, et al. Opposing LSD1 complexes function in developmental gene activation and repression programmes. Nature (2007) 446:882-7. doi:10.1038/nature05671

132. Borggrefe T, Liefke R. Fine-tuning of the intracellular canonical Notch signaling pathway. Cell Cycle (2012) 11:264-76. doi:10.4161/cc.11.2.18995

133. Miele L. Transcription factor RBPJ/CSL: a genome-wide look at transcriptional regulation. Proc Natl Acad Sci U S A (2011) 108:14715-6. doi:10.1073/ pnas. 1110570108

134. Wang H, Zou J, Zhao B, Johannsen E, Ashworth T, Wong H, et al. Genomewide analysis reveals conserved and divergent features of Notch1/RBPJ binding in human and murine T-lymphoblastic leukemia cells. Proc Natl Acad Sci U S A (2011) 108:14908-13. doi:10.1073/pnas.1109023108

135. Zhao B, Zou J, Wang H, Johannsen E, Peng CW, Quackenbush J, et al. Epstein-Barr virus exploits intrinsic B-lymphocyte transcription programs to achieve immortal cell growth. Proc Natl Acad Sci U S A (2011) 108:14902-7. doi:10.1073/pnas.1108892108

136. Graziani I, Eliasz S, De Marco MA, Chen Y, Pass HI, De May RM, et al. Opposite effects of Notch-1 and Notch-2 on mesothelioma cell survival 
under hypoxia are exerted through the Akt pathway. Cancer Res (2008) 68:9678-85. doi:10.1158/0008-5472.CAN-08-0969

137. Parr C, Watkins G, Jiang WG. The possible correlation of Notch-1 and Notch-2 with clinical outcome and tumour clinicopathological parameters in human breast cancer. Int J Mol Med (2004) 14:779-86. doi:10.3892/ijmm.14.5.779

138. Sun Y, Klauzinska M, Lake RJ, Lee JM, Santopietro S, Raafat A, et al. Trp53 regulates Notch 4 signaling through Mdm2. J Cell Sci (2011) 124:1067-76. doi: $10.1242 /$ jcs. 068965

139. Osipo C, Golde TE, Osborne BA, Miele LA. Off the beaten pathway: the complex cross talk between Notch and NF-kappaB. Lab Invest (2008) 88:11-7. doi:10.1038/labinvest. 3700700

140. Raafat A, Lawson S, Bargo S, Klauzinska M, Strizzi L, Goldhar AS, et al. Rbpj conditional knockout reveals distinct functions of Notch4/Int3 in mammary gland development and tumorigenesis. Oncogene (2009) 28:219-30. doi:10.1038/onc.2008.379

141. Robinson DR, Kalyana-Sundaram S, Wu YM, Shankar S, Cao X, Ateeq B, et al. Functionally recurrent rearrangements of the MAST kinase and Notch gene families in breast cancer. Nat Med (2011) 17:1646-51. doi:10.1038/ nm. 2580

142. Yen WC, Fischer MM, Axelrod F, Bond C, Cain J, Cancilla B, et al. Targeting Notch signaling with a Notch2/Notch3 antagonist (tarextumab) inhibits tumor growth and decreases tumor-initiating cell frequency. Clin Cancer Res (2015) 21:2084-95. doi:10.1158/1078-0432.CCR-14-2808

Conflict of Interest Statement: The authors declare that the research was conducted in the absence of any commercial or financial relationships that could be construed as a potential conflict of interest.

Copyright $\odot 2016$ Crabtree, Singleton and Miele. This is an open-access article distributed under the terms of the Creative Commons Attribution License (CC BY). The use, distribution or reproduction in other forums is permitted, provided the original author(s) or licensor are credited and that the original publication in this journal is cited, in accordance with accepted academic practice. No use, distribution or reproduction is permitted which does not comply with these terms. 